\title{
periferio
}

\section{FORMAÇÃO DE PROFESSORES PARA O ENSINO SUPERIOR: DOCÊNCIA NA CONTEMPORANEIDADE}

\author{
Ricardo Santos David ${ }^{1}$ \\ Florida Christian University (FCU) - Uniatlántico
}

\section{Resumo}

Este artigo fala sobre os desafios do trabalho docente no ensino superior e sobre as práticas docentes necessárias para que as ações de ensinar e de aprender sejam verdadeiramente realizadas de forma a possibilitar a construção do conhecimento no ambiente da instituição de ensino superior na atualidade através de teóricos PIMENTA; ANASTASIOU(2002). Nóvoa (2007), Ferreira (2010). Aqui são mostrados os desafios perante os alunos de hoje devido às suas mudanças de comportamentos, de prioridades e da importância que dão para a aprendizagem formal. Questões como: O que é ensinar? E o que é aprender nos dias atuais? Quais estratégias de ensinagem são necessárias para o efetivo aprendizado dos alunos, quais características o docente precisa apresentar para ser considerado um profissional competente, como está o ensino superior na atualidade presentes neste artigo. 0 desenvolvimento de capacidades e habilidades de pensar e aprender estruturados dentro de um ambiente adequado é necessário para promover mudanças e inovações, levando a uma melhoria significativa dentro de sala de aula. Os cursos de ensino superior devem dar o suporte para os novos profissionais e cidadãos. Somente com a prática e desenvolvimento da atividade intelectual realizada de forma concreta e participativa tem-se a formação do ser integral. A metodologia do ensino superior deve levar o estudante a entender os mecanismos que levam ao aprendizado de forma consciente e independente.

Palavras-chave: educação superior; atuação docente; modernidade; profissão docente

\footnotetext{
${ }^{1}$ Coordenador e Pesquisador do Centro de Estudos da Lingua(gem) pela Uniatlántico - América Latina e Espanha. ricardosdavid@hotmail.com.
} 


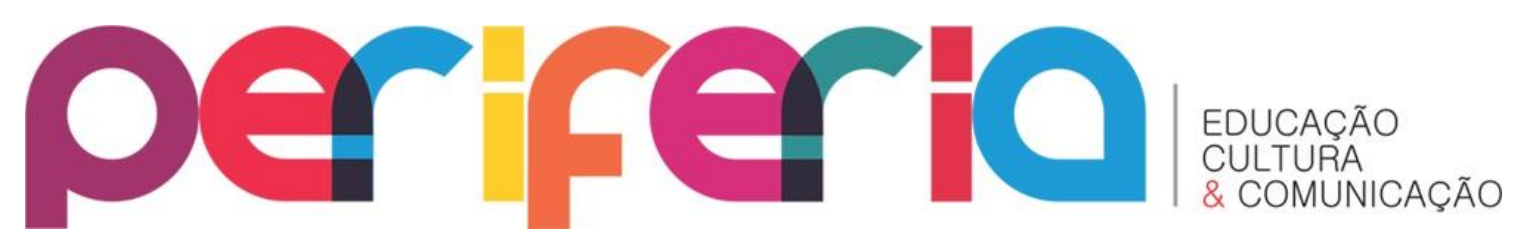

TRAINING OF TEACHERS FOR HIGHER EDUCATION: TEACHING IN CONTEMPORANEITY

\begin{abstract}
This article talks about the challenges of teaching in higher education and on teaching practices necessary for the actions of teaching and learning are truly made in order to enable the construction of knowledge in the institution of higher education in today environment. Here are shown the challenges students face today due to their behavioral changes, priorities and the importance they attach to formal learning through theorists PIMENTA; ANASTASIOU(2002). Nóvoa (2007), Ferreira (2010). Questions like: What teaching? And learning is that nowadays? Teaching and learning strategies which are necessary for effective student learning, which features the teacher must fulfill to be considered a competent professional, as is higher education today, who are commencing students in higher education and what students want and how they relate to the teachers. The development of skills and abilities to think and learn in a structured environment are necessary to promote appropriate changes and innovations leading to a significant improvement in the classroom. The courses of higher education must provide support for the new professionals and citizens. Only with practice and development of intellectual activity conducted in a participatory and practical training has to be integral. The methodology of higher education should lead the student to understand the mechanisms that lead to learning of a conscious and independent.
\end{abstract}

Keywords: higher education; teacher performance; modernity; teaching profession 


\section{periferio}

\section{INTRODUÇÃO}

Transmitir conhecimentos, instruir e mostrar são alguns sinônimos para o verbo transitivo direto "ensinar", conforme Ferreira (2010). Assim como repassar a alguém ensinamentos sobre algo e tornar algo familiar a este alguém, são alguns conceitos apresentados por Houaiss (2009) para a mesma palavra.

Mas, o conceito que melhor remete à ideia de que alguém está ensinando algo importante para outro alguém é o de "educar". Educar, que etimologicamente significa "ir de um lugar para outro" (do latim, educare, inicialmente composta por ex-ducere, ideia de introduzir alguém ao mundo através da instrução e que também pode ser entendido como "levar junto para outro lugar"), (GALLO, 2012). A ideia aqui é pensar numa cena na qual um morador de uma cidade distante recebe um visitante e o leva para conhecer pontos turísticos de sua cidade. E verificar que ao mesmo tempo em que ele apresenta elementos novos a quem não os conhecia, ouve as perspectivas desta pessoa com relação ao passeio e conhece sobre tudo aquilo que ela pesquisou a respeito da cidade antes de estar ali, percebendo então o quanto este visitante se preparou para o passeio. Chega-se então à conclusão de que ambos se beneficiam um do conhecimento do outro. Um se beneficia das sensações e percepções do outro reciprocamente. A relação do educar, sob este ponto de vista, é profundamente humana e leva em consideração que ambas as partes ensinam, mas também aprendem. E não sendo desta forma, não há de fato o exercício da aprendizagem.

Ensinar então significa comunicar, mas não apenas. Ensinar, de acordo com Nóvoa (2007), vai além, pois o docente não pode se posicionar no senso comum, preparando a mesma aula diariamente, utilizando como referências as mesmas estratégias que observou seus próprios professores utilizarem em outras épocas e realidades ou, ao ouvir seus colegas comentando sobre a defasagem de conhecimento dos alunos e sobre o desinteresse que 


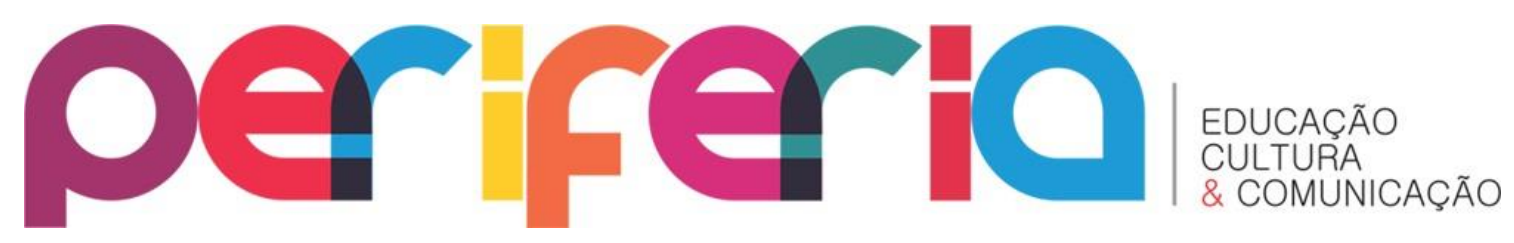

apresentam em sala de aula, preparar unicamente aulas expositivas e automáticas, por considerar que de qualquer forma, se empenhando ou não na busca de estratégias capazes de auxiliar no processo de aprendizagem de seus alunos, estes não se interessarão. Nietzsche (apud DUARTE \& JUNIOR, 2006) afirmava que muito além deste senso comum, a primeira tarefa da educação é ensinar a ver e chamava a atenção para o fato de que ver é coisa complicada, por não ser uma função natural para o ser humano no sentido de que é preciso um mediador entre o objeto de estudo e o aluno para que este possa enxergar o que no objeto está escondido, tendo então a possibilidade de interagir com este objeto.

Alves (2005) diz que os alunos não precisam gostar do que estão vendo, a partir das orientações do professor, mas precisam ser apresentados para o máximo de possibilidades de visões para que possam fazer suas próprias escolhas no futuro.

Pois, ensinar é proporcionar ao aluno o conhecimento da existência e do manuseio do máximo de ferramentas possível e levá-lo a construir seu conhecimento, tendo em vista que o professor não pode transferir-lhe os seus próprios conhecimentos, mas pode e deve ser 0 mediador entre o conhecimento e o aluno. Para tanto, o professor precisa despertar o interesse de quem aprende, precisa saber que existe uma reação/equação entre o que o professor diz com o que o aluno já traz de bagagem para dentro da sala de aula. É necessário levar em consideração o que o aluno já traz de vivência e de história de vida, pois se o que o professor disser não fizer sentido para o aluno dentro de sua realidade e/ou perspectivas, este não poderá transformar aquilo que ouve numa nova ideia, num efetivo aprendizado. Sendo função do professor, ensinar, antes, precisa refletir sobre aquilo que irá ensinar e para quem, e também como e para quê irá fazê-lo.

Porque apenas com esta reflexão inicial possibilitará a si mesmo, também ver e enxergar o aluno com o qual irá desenvolver o processo de aprendizagem permitindo ao aluno o exercício de sua própria visão e tomando o devido cuidado para não "contaminar" o aluno com seu olhar já viciado de 


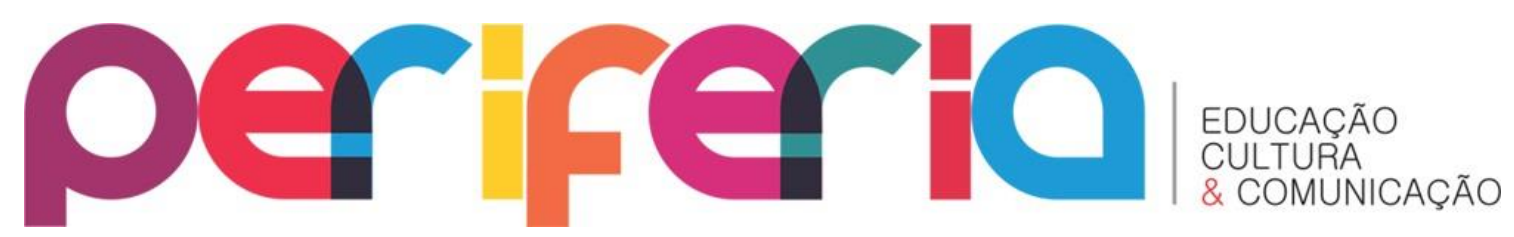

professor. Esta ação é possível com o que Alves (2005) chama de “desensinar”, que seria trabalhar a visão “curta” e limitada com a qual o aluno chega ao ensino superior para aprender o novo e enxergar além daquilo que já existe. Desaprender seria esquecer o que já se aprendeu, para “quebrar o feitiço” da articulação da linguagem que, segundo ele, limita a visão do aluno para o real aprendizado, impedindo-o de desconstruir o que recebeu de informação para reconstruir e produzir novas ideias. Sendo assim, o aluno precisa ter e sentir a liberdade para aprender o novo, para não se limitar àquilo que o professor traz e para conseguir ir além das ideias e das teorias apresentadas, compreendendo assim, coisas que talvez nem o professor tenha compreendido. A ideia seria então, não apenas somar saberes, mas subtraí-los para que coisas novas possam ficar claras e haja então, o real aprendizado para todos os envolvidos.

Já de acordo com Veras (2011), ensinar no ensino superior atualmente caracteriza-se por seu aspecto de capacitação profissional, a partir do qual o professor precisa discutir sobre o tecnicismo da futura profissão de seus alunos, ansiosos em ser competentes em suas almejadas atividades após estarem formados. A postura do professor não deve ser a de "ensinante" nem a de treinador, mas a de "estar com" os alunos, trabalhar com eles, para que o ensinar seja algo vivo e estimulante. Pensar o ensinar desta forma deve estimular os alunos, mas igualmente ao docente, pois ele também, como humano que é, precisa se sentir vivo, fazedor de atividades que the tragam prazer e realização pessoais, e não apenas um cumpridor de regras do espaço onde trabalha ou repetidor de métodos aprendidos quando ele próprio era aluno do ensino superior.

Desta forma, ensinar deve ser parte de um processo criativo, no qual professores e alunos sejam desafiados a todo instante a sempre procurarem mais e, após encontrarem o objeto procurado, tenham a inquietação de procurar por outro, conscientes da importância de mentes ávidas pela construção constante do conhecimento. O professor, inclusive, pode usar a ânsia de conhecer conteúdos novos com a qual o aluno chega ao ensino 


\section{periferio}

superior para mostrar-lhe exemplos de práticas que o auxilie a alcançar o aprendizado permanente e sobre a importância da dúvida para que a geração de novos pensamentos seja possível. É válido chamar a atenção neste ponto para a ideia equivocada, porém existente de que ensinar seja ação de pessoas possuidoras de algum dom. De acordo com Nóvoa (2007), trata-se da perigosa ideia do professor missionário, dotando-o com um dom especial capaz de transformar erros da sociedade em acertos. 0 papel do professor nesta visão, muito parecida com a de um sacerdote, perde sua principal característica de profissional preparado, de mediador, de orientador sobre assuntos de sua especialização e qualificação profissional. Assim, sem o reconhecimento desta qualificação, se um aluno desiste de um curso ou mesmo passa a faltar nele, então o professor é apontado como sendo um pastor que não soube manter suas ovelhas no bom caminho.

As sociedades modernas, principalmente aquelas baseadas no sistema capitalista, exigem dos indivíduos que ela integra, cada vez mais quando se trata de rendimento, excelência, produtividade e qualidade, principalmente quando se trata do mercado de trabalho. Isso contribui consequentemente, como aumento da competição acirrada dentro dessa sociedade fazendo com que cada pessoa, de todas as profissões tenha que estar cada vez mais configurados às novas demandas impostas pelos moldes capitalistas de trabalho.

Essas demandas, por muitas vezes, não são remuneradas de acordo com o tempo e trabalho gasto para atendê-las, ou mesmo, o profissional se quer é reconhecido pelo seu trabalho. É possível observar, portanto, neste contexto que os males sociais cada vez mais aumentam, atingindo cada indivíduo envolvido neste sistema e, como consequência, estes desenvolvem problemas físicos e psicológicos que influenciam em seu desenvolvimento tanto pessoal quanto profissional.

A cada dia que passa exige-se cada vez mais do docente: trabalho docente de qualidade, trabalho administrativo dentro do prazo, observação às dificuldades e particularidades dos alunos em sala de aula, atendimento a pais 


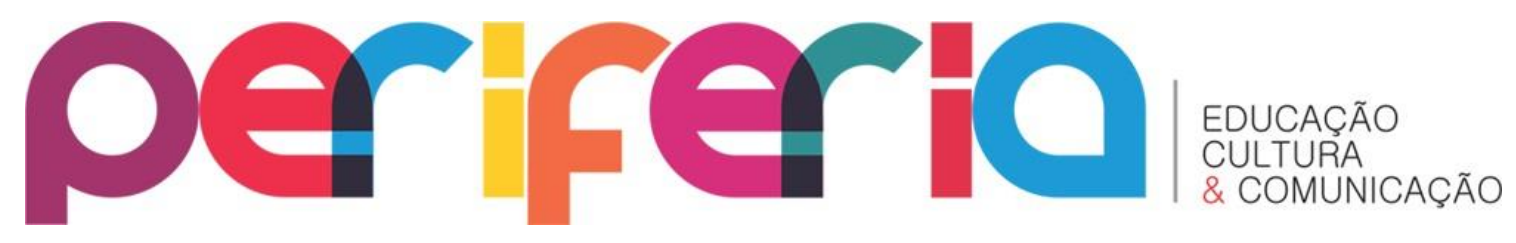

de alunos, melhoria em sua qualificação profissional através de cursos de especialização - sendo que estes, muitas vezes, são pagos pelo próprio docente - dentre outras exigências. $E$ tais demandas nem sempre são recompensadas, pelo menos financeiramente, conforme o tempo e trabalho despendido pelo docente. Dessa forma, o docente, em tentar complementar sua renda, procura uma segunda jornada de trabalho e acumula ainda mais trabalho, estresse dentre outras problemáticas.

Os profissionais do ensino superior precisam ter consciência do que representa estar na universidade atualmente. Para muitos alunos, a oportunidade única ainda, mas por estar em um país onde as desigualdades sociais se refletem na educação, tendo um papel social essencial no desenvolvimento do país, sociedade e história contemporânea.

Por esse motivo são lançadas algumas perguntas como: Quem é o docente universitário de hoje? Qual o perfil exigido?

0 objetivo principal deste trabalho de pesquisa é buscar, da pesquisa documental e bibliográfica, a compreensão e possíveis respostas para estas perguntas sobre a necessária formação e atuação para o docente na educação superior na atualidade.

\section{A IMPORTÂNCIA DA FORMAÇÃO NA DOCÊNCIA DO ENSINO SUPERIOR}

No contexto de ampla discussão acerca da formação do professor universitário e as condições pelas quais esses profissionais ingressam na vida acadêmica surgem reflexões sob os diferentes enfoques e paradigmas relativos aos saberes pedagógicos e epistemológicos que mobilizam a docência gerando assim, uma tensão explícita no bojo das universidades que cada vez mais têm recebido professores sem experiência prévia na função de docente do ensino superior, além dos diversos professores que, apesar de esboçarem um excelente referencial teórico, necessitam, entretanto, rever sua prática pedagógica. Retomar essa temática implica aprofundarmos nossa discussão em torno das exigências cada vez mais complexas na preparação dos professores 


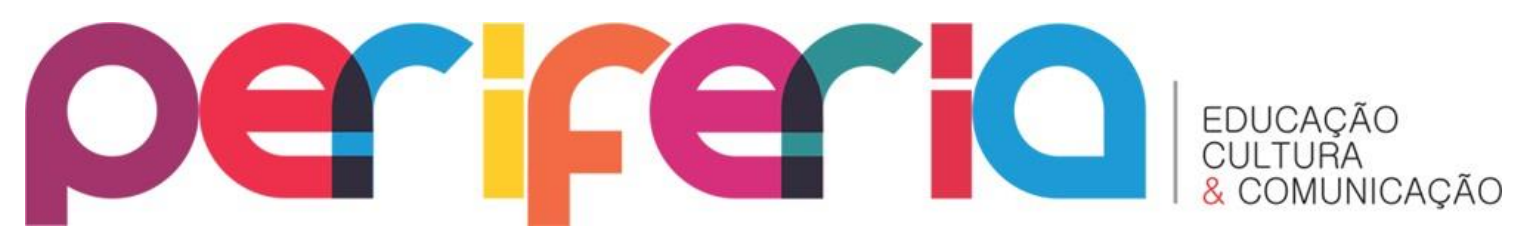

universitários para o ingresso no magistério superior que sobrepassa a formação inicial numa área específica do conhecimento.

Fica nítido, portanto, que a ausência dessa formação pedagógica vem delegar um peso enorme a esses professores frente às interfaces do "que ensinar" "como ensinar" e a "quem ensinar", os quais ao transitarem entre o amadorismo profissional e a profissionalização, confrontam com várias dificuldades que não são previsíveis e passíveis ao exercício da prática docente. No geral, os professores que por razões e interesses variados, adentram no campo universitário, são de variados conhecimentos e áreas de atuação e em sua maioria, não tiveram nenhum contato anterior com os conhecimentos nas áreas das Ciências humanas e sociais, para compreender, interpretar e aplicar a prática, numa perspectiva filosófica e política de educação como processo e produto que as várias correntes de pensamento dão a esses termos.

Partimos desse princípio, percebemos a vivência efetiva que as universidades enfrentam quando o seu corpo docente é composto, em sua maioria, de principiantes na docência do ensino superior e nunca tiveram contato com uma formação pedagógica que abarcasse os conhecimentos teóricos e práticos relativos às questões do ensino e aprendizagem em sua contextualização, tais como: o aluno - sujeito do processo de socialização do saber; o professor - agente de formação, e o contexto-lócus onde ocorre o saber e as relações que se travam entre suas interdependências.

Dessa forma, no percurso de suas ações e no âmago do seu senso comum pedagógico, o docente aloca sua práxis educativa, desarticulada com as finalidades sócio político e culturais do processo educativo.

Sendo assim, é preciso apontar algumas saídas entre as quais, o desenvolvimento profissional, como aporte para o domínio dos saberes didáticos e o entrelaçamento da competência acadêmica com a competência didática. Atentos a essa questão, Pimenta e Anastasiou (2002), referindo-se ao processo de docência do ensino superior, dizem que: 


\section{periferio}

O avançar no processo de docência e do desenvolvimento profissional, mediante a preparação pedagógica não se dará em separado de processos de desenvolvimento pessoal e Institucional: este é o desafio a ser hoje, considerado na construção da docência no ensino superior (p.259).

Essa constatação favorece a discussão da formação continuada em serviço que deve referenciar a pessoa do docente como sujeito que ocupa espaços determinantes à transformação da sociedade, deslocando, assim, em primeira instância, sua preparação pedagógica à conquista desse momento como espaço institucionalizado onde seu desenvolvimento pessoal possa percorrer os diferentes espaços universitários. Para tanto, faz-se necessário considerar, a princípio, que a especialidade da docência oriunda do projeto institucional, cuja habilitação deve vir articulada e legitimada pelo mesmo, concedendo-lhe, assim consistência para o cultivo da competência didático universitária.

Retomando nossa linha de pensamento, compreendemos que a função própria da universidade é proporcionar momentos de reflexões cujo objetivo seja a mediação à construção e reconstrução dos conhecimentos, conjugando a qualidade formal com a qualidade política, componentes intrínsecos à formação docente para delineá-lo do saber pensar como condição subjetiva do homem de fazer sua história para a história; potencializando sua individualidade, acreditando, como Demo (1998), que a universidade é, sobretudo sinônimo de mutações, desafios, adversidades e confrontos com o mundo real. A formação pedagógica, pensada em termos acadêmicos e didáticos, surge num panorama de compreensão sobre qualidade do trabalho docente no recinto da sala de aula, ou seja, no contexto da ação, que não se restringe aos saberes, mas na capacidade do docente de agir em circunstâncias previstas ou não em seu plano de ação.

Nesse sentido, os pressupostos de Perrenoud (2002), quando define competência como a faculdade de mobilizar um conjunto de recursos (cognitivos), visando abordar uma situação complexa e quando referencia em seus escritos as dez novas competências essenciais ao ensino do professor 


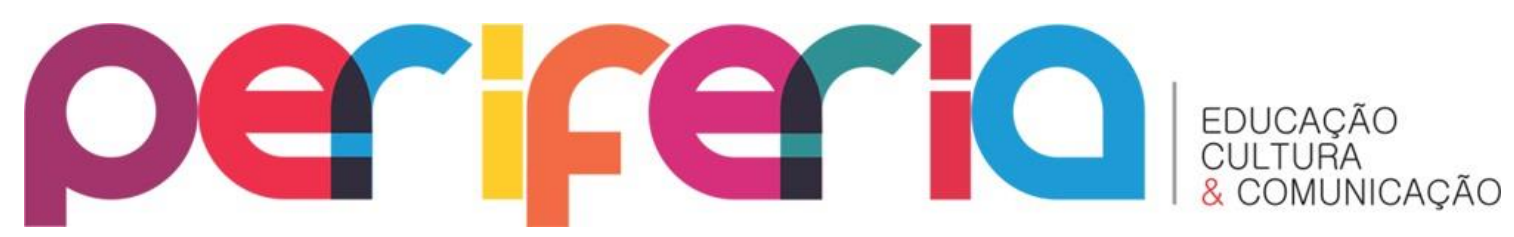

enfatiza o administrar sua própria formação como âncora para que o docente possa navegar os mares mais seguros do ensinar uma vez que, as turbulências da era globalizada, vão exigindo destas mobilizações maiores para a ação, considerando que são os mesmos que constroem e reconstroem seus conhecimentos a partir da práxis.

O objetivo deste capítulo é tratar, brevemente, sobre o papel do docente no processo de ensino e aprendizagem e na educação de forma geral, entendendo o que a sociedade espera do mesmo, suas atribuições e exigências realizadas pelos tempos modernos. Esse resgate se faz necessário para que se entenda a real importância do docente no processo educacional e a razão pela qual ele necessita ser reconhecido, que seu trabalho seja moderado com suas funções de educar, salvaguardando sua qualidade de vida pessoal e profissional.

Pode-se observar, portanto, que atualmente o papel e a atuação do docente não é a mesma que no início e meio do século passado. Neste tempo, segundo Saviani (2008), o docente, sob um prisma tradicionalista, tinha o papel de detentor de todo o conhecimento e depositava nos seus alunos aquilo que havia estudado configurando o que o autor falar de "educação bancária". (FONSECA, 2003.)

Atualmente, pode-se perceber que o docente mudou sua forma de atuação, seja porque os paradigmas educacionais mudaram ou a própria formação do docente mudou. Hoje, o docente é um facilitador no processo de ensino e aprendizagem, pois o ator principal neste processo é o aluno e o docente deve ensiná-lo a pensar, a questionar e a aprender a ler sua realidade, para que possam construir opiniões próprias.

Para que isto ocorra o docente deve, em primeiro lugar, gostar e acreditar naquilo que faz, ou seja, através de seus atos e ações ele servirá de modelo para seus alunos; se ele ensina a refletir ele deve também refletir, se ele ensina a respeitar o próximo ele deve respeitar seus alunos e assim por diante. Deste modo ele está sendo uma prova viva daquilo que está 


\section{periferio}

ensinando, pois bem a sua frente existem seres humanos que estão sendo moldados por ele.

A relação docente/aluno deve ser cultivada a cada dia, pois um depende do outro e assim os dois crescem e caminham juntos. E é nessa relação madura que o docente deve ensinar que a aprendizagem não ocorre somente em sala de aula. Assim, o aluno irá desenvolver um espírito pesquisador e interessado pelas coisas que existem; ele desenvolverá uma necessidade por aprender, tornando-se um ser questionador e crítico da realidade que o circunda (FREIRE, 1996, p. 34).

Dessa forma e diante da quantidade de informações e da facilidade de acesso a estas, deve o docente conduzir o aluno de forma que possa 0 aprendizado ser mútuo e repleto de motivação. 0 docente deve "traduzir" os conteúdos de forma que o aluno se sinta dentro de uma inesquecível "viagem" e dessa forma possa assegurar a produtividade do ensinamento.

O distanciamento entre docente e aluno deve dar lugar a uma relação de proximidade e cumplicidade. Uma proximidade tal que aluno seja levado a querer aprender. A desejar sempre mais e que o educador sinta-se como um elemento de importância fundamental na vida daquele aluno que levará para sempre os ensinamentos adquiridos.

Os docentes devem ser preparados para a arte do ensinar. Não basta ser um bom pesquisador, necessário se faz que seja, também, um bom docente, ou seja, que saiba ensinar e facilitar a construção do conhecimento, ter um bom ou ótimo conhecimento sobre as especificidades do processo de ensino e aprendizagem. (NÓVOA, 2007.)

Existem profissionais extremamente habilitados para militar em suas respectivas áreas e ainda munidos de profundo conhecimento, entretanto limitados quando o assunto é transmitir seus conhecimentos e trabalhar em conjunto com o aluno. Muitas vezes o docente possui conhecimento, mas não sabe ensinar e, muitas vezes, não procurar aprender, se aperfeiçoar.

Enfim, o docente deve ser um aliado na construção do indivíduo e não, simplesmente, um transmissor de disciplinas. 0 docente deve ainda estar apto 


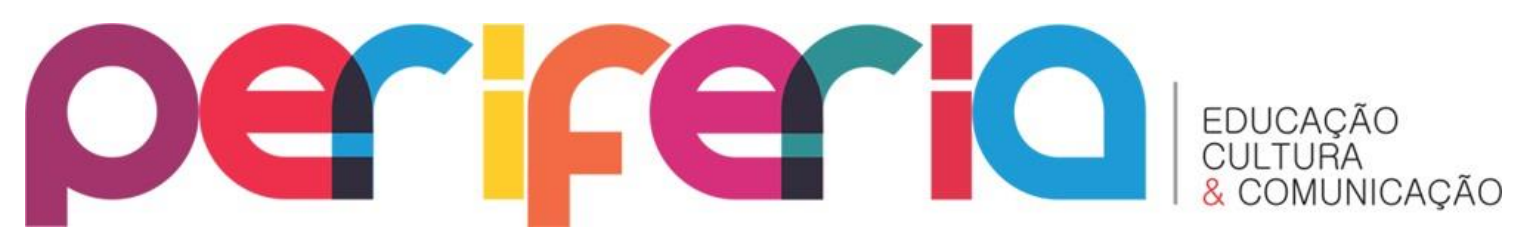

às contínuas mudanças do cotidiano, e na realidade do próprio aluno, auxiliando na formação de cidadãos conscientes de seus direitos e deveres.

É possível observar ainda em outras pesquisas como a de Ruiz (2003) que diz que o docente deve assumir o papel de transformador social e, ainda, que é um ser e profissional político, que deve engajar-se política e socialmente a fim de desenvolver um processo de aprendizagem mais rico e realmente emancipador aos seus alunos.

Existem na própria sociedade outras exigências ao docente. 0 docente não possui somente o papel de educador, de facilitador no processo de ensino e aprendizagem, mas como um administrador das tarefas burocráticas - fazer provas, corrigi-las, passar nota, fazer exames, etc - e também como psicólogo que deve estar sempre em observação dos seus alunos atento a qualquer mudança de comportamento, tratar assuntos com os pais. Existem ainda as exigências de uma formação continuada, em que o docente deve estar constantemente se reciclando, fazendo cursos, se especializando e, muitas vezes, com seu próprio dinheiro, pois muitas instituições não pagam nem se quer parcialmente os cursos realizados pelos docentes. E a remuneração não é condizente com tantas tarefas, tantas exigências, o que desestimula o docente, deteriorando não somente sua prática docente, bem como sua própria saúde.

\section{DOCENCIA NO ENSINO SUPERIOR}

Conforme divulgação do Censo (2010), a atuação dos professores do ensino superior na atualidade não se restringe à graduação, mas incorpora também atividades na pós-graduação e pesquisa, havendo então a possibilidade de diversidade de ambientes de estudo, mas, por outro lado, sobrecarregando o docente. E de acordo com Masetto (2003), o século XX chegou ao fim apresentando algumas mudanças no ensino superior e uma delas diz respeito ao perfil do professor. 


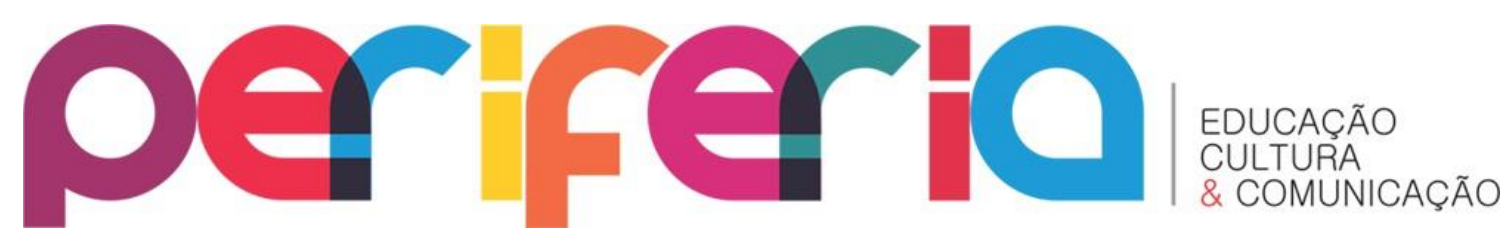

0 docente do ensino superior deixou de ser o foco no cenário do ensino e, conjuntamente com o aluno, passou a ocupar o centro deste cenário, passando ambos a ser coparticipantes do mesmo processo. Mudou-se também a atitude do professor, deixando de ser unicamente um especialista em alguma área de atuação no mercado de trabalho, capaz de ensinar, e transformando-se em um profissional da área de ensino, capaz de motivar e incentivar o aluno no processo de aprendizagem. 0 professor deixou de ser a única fonte de informações do aluno, e passou a explorar com ele outros ambientes de aprendizagem, valorizando então o processo coletivo, que consiste em aprender com outros alunos, com outros professores de outras áreas e com profissionais não acadêmicos, estendendo o ambiente de aprendizagem para a sociedade de modo geral.

Desta forma, buscou-se desenvolver competências próprias para a atividade da docência no ensino superior, entendendo-se que para ser um bom docente, muito mais do que ser um especialista em alguma área ou ser um reconhecido profissional no mercado de trabalho, há a necessidade de conhecer especificidades que levam estes profissionais à competência na área na qual atuam e não apenas pessoas dispostas a repassar sua experiência profissional fora do ambiente do ensino superior a alunos cuja pretensão seja saber exatamente como estes profissionais trabalham para ter condições de replicar suas práticas no futuro exercício de suas funções após estarem formados. Para o autor, a concepção de competência é uma série de aspectos que se apresentam e se desenvolvem conjuntamente, como por exemplo, saberes, conhecimentos, valores, atitudes e habilidades. Possuir características de um bom docente, neste sentido, é ter domínio de conhecimentos básicos em sua área de atuação com experiência no exercício profissional, incluindo pesquisa e entendendo por pesquisa, reflexões críticas, produção de textos, preparação de trabalhos específicos para apresentações em congressos, redação de capítulos de livros, dentre outras atividades.

É também possuir domínio na área pedagógica, sabendo atuar com o processo de ensino-aprendizagem e ter condições de utilizar estes 


\section{periferio}

conhecimentos pedagógicos para gerir o currículo do curso ao qual se propõe a ensinar, possuindo clareza sobre a relação professor-aluno e aluno-aluno no processo de aprendizagem e conhecendo bem a tecnologia educacional do momento histórico do qual faz parte. O bom docente do ensino superior então, não ensina apenas com foco no mercado de trabalho, até porque não tem como saber como estará este mesmo mercado quando seus alunos se formarem. 0 bom docente trabalha para direcionar a aprendizagem de seus alunos através dos objetivos da instituição de ensino na qual trabalha, com autonomia para encaminhá-los além das exigências mercadológicas. Sempre atualizado com os acontecimentos do mundo contemporâneo e interessado em conhecer seus alunos, o bom docente será capaz de orientá-los e de formá-los de maneira que possam se posicionar social e profissionalmente em suas carreiras no futuro.

Para Masetto,

...só recentemente os professores universitários começaram a se conscientizar de que seu papel de docente do ensino superior, como o exercício de qualquer profissão, exige capacitação própria e específica que não se restringe a ter um diploma de bacharel, ou mesmo de mestre ou doutor, ou ainda apenas o exercício de uma profissão. Exige tudo isso, e competência pedagógica, pois ele é um educador. (2003, p. 13).

Havendo, portanto, características a trabalhar na profissão docente pela capacidade que precisam possuir em facilitar o aprendizado, como por exemplo, a coerência entre discurso e ação, a segurança e a abertura a críticas e às propostas dos alunos (entendida como capacidade de diálogo), a clareza e a objetividade na transmissão de informações, a preocupação com os alunos e com seus interesses, o incentivo à participação e à capacidade de coordenação das atividades, a competência específica na área do conhecimento, o relacionamento pessoal e a paixão pela docência. 0 aluno e a sociedade não podem entender o papel do professor como solitário no processo de aprendizagem, pois esta ideia descaracteriza a profissão docente 


\section{periferio}

e profissional é o que o professor precisa ser, antes de tudo, para que possa desenvolver um bom trabalho, um trabalho dito marcante.

Entendendo que professor e aluno são indispensáveis para o caminho do conhecimento e para que a ensinagem seja real e concreta, compreende-se que a missão da educação no ensino superior deve ser a de contribuir para a autoformação da pessoa, para ensinar a assumir a condição humana, ensinar a viver e instruir sobre como se tornar um cidadão numa época que exige a construção de uma identidade que seja ao mesmo tempo nacional e planetária. Além disso, Morin (2003) destaca que a missão do didatismo deve ser encorajar o autodidatismo, despertando, provocando e favorecendo a autonomia de espírito. Então ensinar não é transmitir um mero saber, mas apresentar uma cultura que permita compreender a condição humana e auxilie na formação de um pensamento autônomo e livre. Assim, se a instituição de ensino superior estiver centrada na aprendizagem e não apenas com foco no mercado de trabalho, poderá se preocupar com os alunos, com a sociedade e com o corpo docente, ao invés de preocupar-se apenas com uma esfera da sociedade em detrimento de outra igualmente importante. A importância do foco na aprendizagem destaca-se porque ela aborda um todo de conhecimentos e a necessidade de aprender a aprender como a construção destes conhecimentos deve acontecer. 0 espaço do ensino superior então deve ser um espaço onde os alunos aprendem a pesquisar, a questionar, a aprender, a estudar, a respeitar, a ver e a trabalhar.

A educação superior vem sendo muito debatida devido a grande importância e valorização do conhecimento e relação deste com o desenvolvimento econômico, político, social das sociedades.

Podemos perceber através da nossa pesquisa que as instituições de ensino superior, estão em processo de reconstrução e reformulação referente a seu papel e função. Cada vez mais é verificada a necessidade de uma reforma educacional em nosso país, para tornar capaz de promover a inclusão social e o desenvolvimento democrático em nossas instituições, possibilitando 


\section{periferio}

aos alunos o acesso e a permanência e aos docentes a possibilidade de pensar a educação superior hoje.

A história da educação no Brasil nos revela que a formação do profissional superior e a sua atuação são importante, principalmente para a atualidade, em busca de uma educação e docência superior transformadora. (CUNHA, 2000)

Um desses questionamentos atuais é o novo rumo da formação docente. Tendo como desafio, a formação, revendo sua concepção, objetivos e funções, criando outras formas de desenvolver a formação continuada. (ABRAMOWICZ, 2001, p.137).

Atualmente o crescimento da profissão docente, é proporcional à valorização pela formação qualificada e conhecimento profissional mais aprofundado, através dos cursos superiores, da titulação exigida para um profissional considerado cada vez mais competente.

Dessa forma, cabe também aos Programas de Pós-graduação proporcionar um espaço para a discussão e o pensar a formação e a atuação docente, o educador do ensino superior tem crescente interesse pela docência superior, exigências que estabelecem uma necessidade pessoal ou institucional de um profissional que compreenda e conheça a prática pedagógica, contexto e problemas da educação superior.

Os futuros profissionais da educação superior trazem consigo experiências escolares, constituindo em modelos, positivos ou negativas, de atuação docente, sendo parte importante da sua trajetória de vida. Apesar os docentes representem modelos, podemos verificar que é preciso muito mais para poder chegar a uma docência bem qualificada, na educação superior, resultando em um processo de construção e formação constantes.

O profissional da educação superior não pode estar desatento à necessidade de uma educação transformadora, às exigências institucionais ou sociais do momento histórico, devendo procurar, refletir sobre qual é o seu papel e sua função, os limites e possibilidades de uma atuação transformadora. 


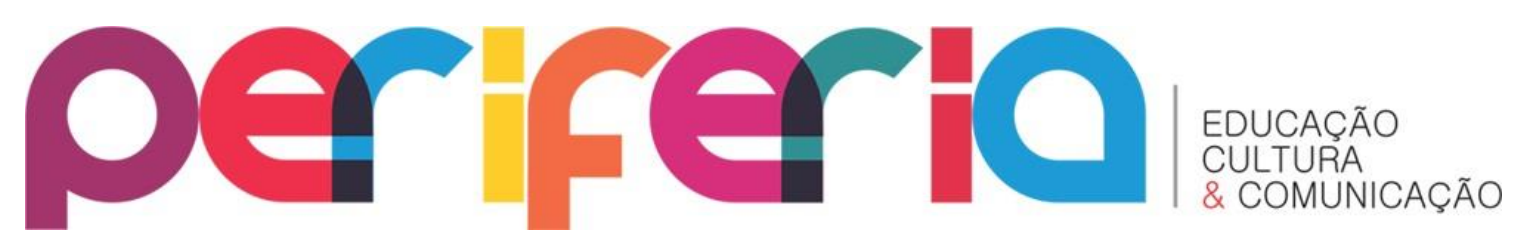

\section{CONSIDERAÇÕES FINAIS}

Conforme visto no estudo o papel que o docente deve desempenhar numa sociedade moderna é complexo, diante das grandes demandas que a sociedade, de cunho capitalista, coloca sobre os profissionais e a todos os indivíduos de uma forma geral.

Exige-se, pela sociedade, desempenho, rendimento, habilidades para múltiplas tarefas, humanização, competição, etc. Ao mesmo momento que ao profissional é exigido que ele seja eficaz e que produza mais, em menos tempo, e com maior qualidade, que ele seja bem qualificado, exige-se que ele seja humano, que seja um ser social, um ser político, que esteja preparado para modificar sua realidade.

Com o docente, essas demandas são ainda maiores. Ao mesmo tempo em que este deve ser um educador, que hoje é considerado como um facilitador no processo de ensino e aprendizagem do aluno, ele também é, pelo menos em parte, um pouco psicólogo, pois deve observar as dificuldades dos alunos e da comunidade. 0 docente deve realizar funções administrativas como confecção de provas, testes, passar notas, participar de reuniões pedagógicas, etc. O docente deve, ainda, estar sempre atualizado, fazer cursos, se especializar, fazer mestrado, doutorado, etc. Não importando se ele possui recursos financeiros ou não para este fim. E ainda, o docente deve ser criativo em suas aulas sendo que estas devem ser de qualidade, motivadoras, que estimulem os estudantes a querer construir e/ou buscar o conhecimento.

Porém, quando chega a se recompensar o docente por todas essas exigências, pode-se dizer que este é um dos profissionais pior remunerados pelo o que o trabalho exige e pelo tempo despendido para o mesmo, sem falar do desgaste físico e emocional que é imposto ao docente. Com salários baixos, o docente procura mais trabalho para compensar sua renda, o que aumenta seu nível de estresse. 


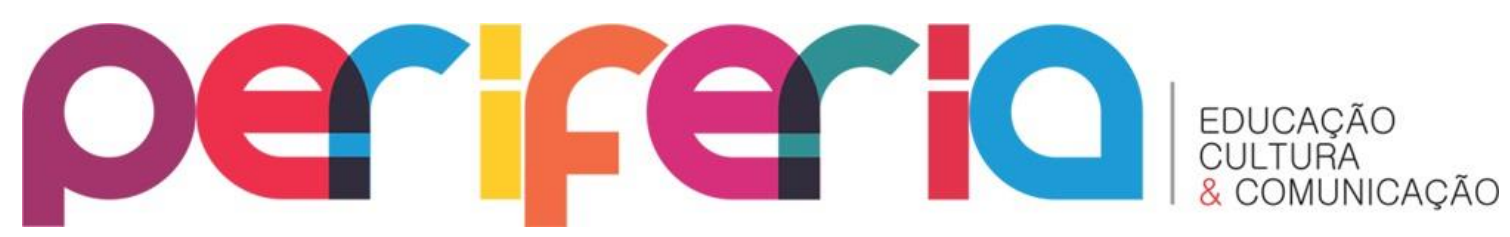

O docente hoje é cobrado por um trabalho que deve ser coletivo, mas que, muitas vezes é possível, por um aprofundamento intelectual e cultural que não tem acesso, diante das condições de trabalho limitadas; e por uma participação institucional não permitida, assim como por uma atuação didático-pedagógica de excelente qualidade.

Estes são desafios que permanecem para a construção das trajetórias docentes, construção esta que acontece individual e coletivamente, em diferentes contextos e condições, com outros seres humanos que estão participando das possíveis mudanças. Permanece a temporalidade do homem, um dia permanecerá apenas sua história, sua trajetória de vida, memórias, marca, influenciando outros homens, provocando e promovendo possíveis mudanças.

São de este olhar que se procurou compor este trabalho, das análises e reflexões de homens concretos, vivos, tecendo dia-a-dia suas histórias, suas trajetórias docentes, conscientes de sua participação no mundo. Propomo-nos apresentá-lo como contribuição para o aprofundamento das questões quanto ao papel da educação superior, das instituições e do profissional, educador em nível superior.

\section{REFERÊNCIAS}

ABRAMOWICZ, M. A importância dos grupos de formação reflexiva docente no interior dos cursos universitários. In: CASTANHO, S.; CASTANHO, M. E. Temas e textos em Metodologia do Ensino Superior. Campinas: Papirus, 2001. p. 137142.

ALVES, R. Koan. In: ALVES, R. A escola com que sempre sonhei sem imaginar que pudesse existir. São Paulo: Papirus, 2005.

BRASIL. Lei n 9.394/96. Lei de Diretrizes e Bases da Educação Nacional, 1996.

CENSO DA EDUCAÇÃO SUPERIOR 2010. Divulgação dos principais resultados do Censo da Educação Superior. 2010. INEP, 2011. Disponível em:<http://portal.mec.gov.br:80/index.php?option=com_content\&view=articl eftid=17212>. Acesso em: 07 jul. 2013. 




CUNHA, L. A. Ensino Superior e Universidade no Brasil. In: LOPES, E. M. T.; MENDES, L.; VEIGA, C. G. (Orgs.). 500 anos de Educação no Brasil. Belo Horizonte: Autêntica, 2000.

DEMO, P. Educar pela pesquisa. 03 ed. Campinas, SP: Autores associados, 1998.

DUARTE JUNIOR, J. F. O sentido dos sentidos: a educação (do)sensível. Curitiba: Criar Edições, 2006.

FERREIRA, A. B. de H.. Dicionário da Língua Portuguesa. Rio de Janeiro: Positivo, 2010.

FREIRE, P. Pedagogia da Autonomia: saberes necessários à prática educativa. São Paulo: Paz e Terra, 1996. (Coleção Leitura)

FONSECA, V. da. Tendências Futuras da Educação Inclusiva. Educação, Porto Alegre, v.49. Mar. 2003.

GALLO, S. As múltiplas dimensões do aprender. São Paulo: COEB 2012 (Congresso de Educação Básica: Aprendizagem e Currículo), 2012. Disponível em:

$<$ http://www.pmf.sc.gov.br/arquivos/arquivos/pdf/13_02_2012_10.54.50.a0a c3b8a140676ef8ae0dbf32e662762.pdf> . Acesso em: 28 set. 2013.

MASETTO, M. T. Competência Pedagógica do Professor Universitário. São Paulo: Summus, 2003.

MORIN, E. A cabeça bem-feita: repensar a reforma, reformar o pensamento. Tradução Eloá Jacobina. 09. ed. Rio de Janeiro: Bertrand Brasil. 2004. p.128.

- Os sete saberes necessários à educação do futuro. Tradução de Catarina Eleonora F. da Silva e Jeanne Sawaya; revisão técnica de Edgard de Assis Carvalho. 08. ed. São Paulo: Cortez, Brasília, DF: UNESCO. 2003. p.118.

NÓVOA. A. Desafios do trabalho do professor no mundo contemporâneo. São Paulo: Sindicato dos Professores de São Paulo, 2007.

PERRENOUD, P. Práticas pedagógicas, profissão docente e formação: perspectivas sociológicas. Lisboa: Dom Quixote, 1993. 2002. . Dez novas competências para ensinar: Porto Alegre, RS: Artmed, 


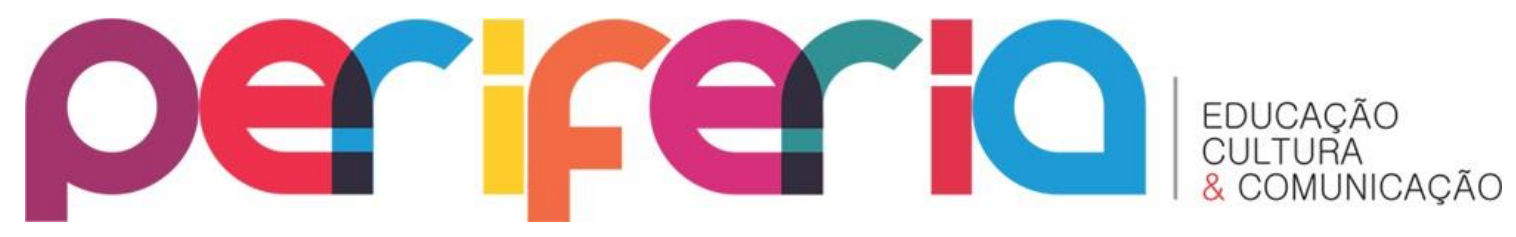

PIMENTA, S.G.; ANASTASIOU, L. das G. C. Docência no ensino superior. São Paulo: Cortez, 2002.

RUIZ, M.J.F. O papel social do professor: uma contribuição da filosofia da educação e do pensamento freireano à formação do professor. Revista Iberoamericana de Educación, n.33, 2003. p.55-70

SAVIANI, D. A pedagogia no Brasil: história e teoria. Campinas: Autores Associados, 2008.

SELVA, G. Ser professor no Brasil: história oral de vida. 02. ed. Campinas: Papirus, 2003.

VERAS, M. Inovação e métodos de ensino para nativos digitais. São Paulo: Atlas, 2011. 